\title{
Protein and mRNA expression of folic acid-associated enzymes as biomarkers for the cytotoxicity of the thymidylate synthase-targeted drugs, pemetrexed and $S-1$, in non-small cell lung cancer
}

\author{
MADOKA KIMURA $^{1}$, FUMIO IMAMURA ${ }^{1}$, TAKAKO INOUE $^{1}$, KAZUMI NISHINO $^{1}$, JUNJI UCHIDA ${ }^{1}$, \\ TORU KUMAGAI ${ }^{1}$, JIRO OKAMI ${ }^{2}$, MASAHIKO HIGASIYAMA ${ }^{2}$ and SHINGO KAMOSHIDA ${ }^{3}$ \\ Departments of ${ }^{1}$ Thoracic Oncology and ${ }^{2}$ Thoracic Surgery, Osaka Medical Center for Cancer \\ and Cardiovascular Diseases, Osaka 537-8511; ${ }^{3}$ Laboratory of Pathology, Division of Medical Biophysics, \\ Kobe University Graduate School of Health Sciences, Kobe, Hyogo 654-0142, Japan
}

Received July 6, 2016; Accepted March 15, 2017

DOI: $10.3892 / \mathrm{mco} .2017 .1262$

\begin{abstract}
The thymidylate synthase (TS)-targeted drugs, pemetrexed and $\mathrm{S}-1$, exert an important role in advanced non-small cell lung cancer (NSCLC) treatment; folic acid-associated enzymes are expected to behave as biomarkers, although their role has yet to be fully elucidated. In the present study, a single-institutional prospective analysis, in which the mRNA and protein expression levels of five folic acid-associated enzymes were evaluated with surgical specimens of NSCLC, was performed. Drug sensitivity was evaluated using a collagen gel droplet-embedded culture drug sensitivity test (CD-DST) in vitro. A total of 50 patients with NSCLC were enrolled, and the mRNA and protein expression levels of five enzymes were assessed in 47 and 46 patients, respectively. A significant association was identified between mRNA and protein expression in TS $(r=0.6266)$, but the correlation between mRNA and protein expression levels for the other four enzymes was poor. TS mRNA expression was significantly higher in poorly differentiated tumors compared with moderately differentiated tumors $(\mathrm{P}=0.0399)$. TS protein expression was significantly higher in patients with pleural invasion or lymphatic invasion compared with those lacking them $(\mathrm{P}=0.027$ and 0.030 , respectively). $\mathrm{CD}$-DST revealed that none of the tumors that were sensitive to pemetrexed, but not
\end{abstract}

Correspondence to: Dr Fumio Imamura, Department of Thoracic Oncology, Osaka Medical Center for Cancer and Cardiovascular Diseases, 1-3-3 Nakamichi, Higashinari-ku, Osaka 537-8511, Japan E-mail: imamura-fu@mc.pref.osaka.jp

Key words: thymidylate synthase, dihydropyrimidine dehydrogenase, protein expression, mRNA expression, pemetrexed, S-1, non-small cell lung cancer, collagen gel droplet-embedded culture drug sensitivity test in vitro, immunohistochemical staining to $\mathrm{S}-1$, were well differentiated, whereas none of the tumors that were sensitive to $\mathrm{S}-1$, but not to pemetrexed, were poorly differentiated. More prominent vascular invasion was observed in the tumors that were sensitive to $\mathrm{S}-1$. The only factors that exhibited the potential to discriminate the cytotoxicity of pemetrexed from S-1 were tumor differentiation grade and vascular invasion.

\section{Introduction}

Cytotoxic drugs continue to serve a critical role in the treatment of advanced non-small cell lung cancer (NSCLC). However, the results of chemotherapy remain unsatisfactory. One possible way to improve the efficacy of cytotoxic chemotherapy would be to optimize it according to the target molecules. Thymidylate synthase (TS) is one of the target molecules in chemotherapy. Pemetrexed and S-1 are available in Japan, and TS is one of their main targets. A large body of clinical data is available on these two drugs in combination with platinum as a front-line treatment or monotherapy; however, the response rates are $\sim 10-30 \%$, and the efficacy of these drugs remains limited (1-6). It is well established that these two drugs have different profiles of antitumor activity, as revealed most characteristically by the fact that $\mathrm{S}-1$ has cytotoxic activity for squamous cell carcinoma (Sq), whereas pemetrexed does not. Due to the presence of a well-characterized target molecule, TS inhibitors are good candidates for optimization in lung cancer. Although TS activity regulates the antitumor effect of these drugs in vitro, the prediction of clinical efficacy of these drugs by measuring $\mathrm{TS}$ has not yet been proven to be successful. One reason for this failure is that the activities of these drugs are also modified by folic acid-associated enzymes, such as dihydropyrimidine dehydrogenase (DPD), folylpolyglutamate synthetase (FPGS), $\gamma$-glutamyl hydrolase (GGH) and dihydrofolate reductase (DHFR) (7-10).

In the majority of the studies reported thus far, the activities of the folic acid-associated enzymes were measured 
either by their protein expression or by mRNA expression. However, it has yet to be elucidated whether these two factors correlate well in lung cancer. In addition, though the Dannenberg tumor profile method is frequently used for the semi-quantitation of mRNA expression, its sensitivity is insufficient to measure mRNA expression in low-volume tumor materials. It is also problematic to adopt the clinical effect of folic acid-associated enzymes on the cytotoxicity of a chemotherapeutic agent, since the clinical effect of a drug is determined not only by the direct sensitivity of the tumor to the drug, but also by the drug concentration at the target lesions. The latter clearly depends on multiple factors, including serum concentration, drug metabolism, the vasculature of tumors, and the activity of transporting the drug to tumor cells.

In the present study, a single-institutional prospective analysis was performed in which the mRNA and protein expression levels of folic acid-associated enzymes were evaluated with surgical specimens of NSCLC. To attain a highly sensitive measurement of mRNA, the TaqMan array method was adopted, which enables the measurement of more diverse gene expression than reverse transcription-polymerase chain reaction (RT-PCR). Drug sensitivity was evaluated using a collagen gel droplet-embedded culture drug sensitivity test (CD-DST) in vitro, which enables the evaluation of drug sensitivity in primary cultured tumor cells. The main purpose of the present study was to determine the parameters to optimize the usage of pemetrexed and S-1 in the treatment of non-Sq NSCLC, paying particular attention to folic acid-associated enzymes.

\section{Materials and methods}

Patients and surgical samples. The representative eligibility criteria for the present study were as follows: i) that sufficient surgical tumor specimens for the analysis of mRNA and immunohistochemical (IHC) staining were available; ii) that the results of the CD-DST for both pemetrexed and S-1 were available; and iii) that written informed consent had been given. Patients who had received chemotherapy and/or radiation therapy prior to surgical resection were excluded. The in-house institutional review board of the Osaka Medical Center for Cancer and Cardiovascular Diseases approved the present study. In our hospital, surgical samples were collected from the patients on their providing consent, and the CD-DST was performed for surgical specimens from the patients who had consented to the test. Surgical samples and clinical data were collected from consecutive patients with non-Sq NSCLC who had undergone surgical resection at Osaka Medical Center for Cancer and Cardiovascular Diseases between 2009 and 2012, and who met the eligibility criteria.

Analysis of mRNA. Representative hematoxylin and eosin-stained slides from formalin-fixed, paraffin-embedded (FFPE) specimens were reviewed by a pathologist for a manual macrodissection of tumor tissue. Tumor tissue was selected and dissected using a scalpel. RNA was isolated from tumor tissue using an RNeasy FFPE kit (Qiagen, Chatsworth, CA, USA). cDNA was prepared using a High Capacity
Reverse Transcription kit (Life Technologies; Thermo Fisher Scientific, Inc., Waltham, MA, USA) according to the manufacturer's protocol.

The expression levels of five genes were determined using TaqMan quantitative RT-PCR (RT-qPCR; TaqMan array card; Life Technologies; Thermo Fisher Scientific, Inc.) following TaqMan assay-based pre-amplification. Briefly, cDNA $(2.5 \mu \mathrm{l})$ was pre-amplified using TaqMan $2 \mathrm{X}$ PreAmp Master mix (Life Technologies; Thermo Fisher Scientific, Inc.) and a pool of TaqMan Gene Expression assays $(0.2 \mathrm{X})$ in a $10 \mu \mathrm{l} \mathrm{PCR}$ reaction. The pre-amplification cycling conditions were as follows: $95^{\circ} \mathrm{C}$ for $10 \mathrm{~min}$, followed by 14 cycles of $95^{\circ} \mathrm{C}$ for $15 \mathrm{sec}$, and $60^{\circ} \mathrm{C}$ for $4 \mathrm{~min}$. An amplified cDNA sample was diluted 20 times in Tris-EDTA (TE) buffer (Sigma-Aldrich Co., LLC., Tokyo, Japan). Amplified cDNA (25 $\mu \mathrm{l})$ was added to $25 \mu \mathrm{l}$ ribonuclease (RNase)-free water and $50 \mu 12 \mathrm{X}$ TaqMan Gene Expression Master mix (Life Technologies; Thermo Fisher Scientific, Inc.). The mixture was subsequently transferred to a loading port for the TaqMan array card (LDA). The array card was centrifuged twice (both times, $331 \mathrm{x} \mathrm{g}$ for $2 \mathrm{~min}$ at room temperature), sealed, and PCR amplification was performed using the ABI Prism 7900HT Sequence Detection System (Applied Biosystems; Thermo Fisher Scientific, Inc.) under the following thermal cycling conditions: $50^{\circ} \mathrm{C}$ for $2 \mathrm{~min}$ and $94.5^{\circ} \mathrm{C}$ for $10 \mathrm{~min}$, followed by 40 cycles of $97^{\circ} \mathrm{C}$ for $30 \mathrm{sec}$ and $59.7^{\circ} \mathrm{C}$ for $1 \mathrm{~min}$. The array card included $\beta$-actin (ACTB) as the reference, based on its proven role as a housekeeping gene $(11,12)$. The cycle threshold $(\mathrm{Cq})$ value, which is inversely proportional to the quantity of cDNA, was calculated (13). The gene expression (relative mRNA) levels were expressed as the ratios (the differences between the $\mathrm{Cq}$ values) between the gene of interest and the reference gene.

Analysis of protein expression. Another set of FFPE specimens was sent to the SRL laboratory (Tokyo, Japan) for IHC analysis. The expression of the TS, DPD, DHFR, FPGS, and GGH proteins in tumor cells was semi-quantitatively evaluated using a histological score (IHC score) by two independent pathologists. The staining intensity was graded by four steps as $0,1,2$, and 3 for no, weak, moderate, and strong staining, respectively. This score was multiplied by the percentage of positive tumor cells (possible range, 0-300) to produce the IHC score.

$C D-D S T$. The CD-DSTs for pemetrexed and S-1 were performed as described previously (14-16). Our previous studies have revealed how CD-DST data are useful for predicting the clinical effect of cytotoxic drugs for NSCLC and gastric cancer, at least in part $(14,16)$.

Statistical analysis. Categorized data were analyzed using the t-test, Tukey's honest significant difference test, Fisher's exact test, or the chi-square test, depending on the number of groups to be analyzed. The Wilcoxon test was used to assess correlations between the baseline groups, and $\mathrm{P}<0.05$ was considered to be statistically significant. Correlation coefficients ( $\mathrm{r}$ ) between the mRNA expression and IHC scores for the five enzymes were calculated using the Pearson product-moment correlation 
Table I. Association between patient characteristics and the enzymes.

A, Association by mRNA expression

\begin{tabular}{|c|c|c|c|c|c|}
\hline Feature (n) & $\mathrm{TS}$ & DPD & FPGS & GGH & DHFR \\
\hline Total (47) & $2.2 \pm 2.1$ & $11.3 \pm 6.2$ & $1.2 \pm 0.5$ & $0.3 \pm 0.3$ & $2.2 \pm 1.1$ \\
\hline \multicolumn{6}{|l|}{ Gender } \\
\hline Female (26) & $2.1 \pm 2.2$ & $11.4 \pm 6.9$ & $1.1 \pm 0.5$ & $0.3 \pm 0.4$ & $2.2 \pm 1.2$ \\
\hline Male (21) & $2.4 \pm 2.1$ & $11.2 \pm 5.4$ & $1.3 \pm 0.5$ & $0.3 \pm 0.3$ & $2.2 \pm 1.0$ \\
\hline \multicolumn{6}{|l|}{ Age, years } \\
\hline$<70(33)$ & $2.3 \pm 2.2$ & $12.0 \pm 7.0$ & $1.2 \pm 0.6$ & $0.3 \pm 0.4$ & $2.4 \pm 1.2$ \\
\hline$\geq 70(14)$ & $2.1 \pm 1.9$ & $9.6 \pm 3.1$ & $1.1 \pm 0.5$ & $0.2 \pm 0.2$ & $1.8 \pm 0.8$ \\
\hline \multicolumn{6}{|l|}{ Histology subtype } \\
\hline Papillary (23) & $1.8 \pm 1.6$ & $11.0 \pm 5.7$ & $1.2 \pm 0.6$ & $0.2 \pm 0.2$ & $2.0 \pm 0.9$ \\
\hline Acinar (17) & $2.6 \pm 2.4$ & $11.2 \pm 5.2$ & $1.3 \pm 0.4$ & $0.3 \pm 0.2$ & $2.5 \pm 1.4$ \\
\hline Solid (3) & $2.1 \pm 1.2$ & $11.3 \pm 8.0$ & $1.00 \pm 0.5$ & $0.3 \pm 0.1$ & $2.0 \pm 1.5$ \\
\hline Lepidic (2) & $2.1 \pm 1.3$ & $20.0 \pm 16.4$ & $1.3 \pm 0.5$ & $0.6 \pm 0.5$ & $2.0 \pm 0.9$ \\
\hline Lepidic + papillary (1) & 0.7 & 6.2 & 1.0 & 0.3 & 1.4 \\
\hline Other (1) & 8.5 & 6.7 & 0.5 & 2.0 & 3.2 \\
\hline Grade of differentiation & a & & & & \\
\hline $1(2)$ & $0.9 \pm 0.3$ & $18.9 \pm 17.9$ & $1.3 \pm 0.5$ & $0.3 \pm 0.0$ & $2.0 \pm 0.9$ \\
\hline $2(27)$ & $1.7 \pm 1.7$ & $10.4 \pm 4.7$ & $1.2 \pm 0.5$ & $0.3 \pm 0.2$ & $2.0 \pm 1.1$ \\
\hline $3(18)$ & $3.1 \pm 2.6$ & $11.9 \pm 6.5$ & $1.1 \pm 0.6$ & $0.4 \pm 0.4$ & $2.5 \pm 1.1$ \\
\hline \multicolumn{6}{|l|}{ Pleural invasion } \\
\hline $0(27)$ & $1.7 \pm 1.7$ & $11.0 \pm 5.8$ & $1.2 \pm 0.5$ & $0.3 \pm 0.4$ & $2.1 \pm 1.2$ \\
\hline $1(14)$ & $2.8 \pm 2.3$ & $11.5 \pm 6.8$ & $1.3 \pm 0.6$ & $0.3 \pm 0.2$ & $2.3 \pm 0.8$ \\
\hline $2(3)$ & $2.9 \pm 2.4$ & $9.1 \pm 3.1$ & $0.9 \pm 0.3$ & $0.3 \pm 0.2$ & $2.3 \pm 1.9$ \\
\hline $3(3)$ & $3.5 \pm 3.9$ & $15.6 \pm 10.0$ & $1.0 \pm 0.2$ & $0.2 \pm 0.2$ & $2.5 \pm 1.3$ \\
\hline \multicolumn{6}{|l|}{ Blood vessel invasion } \\
\hline $0(29)$ & $2.2 \pm 2.3$ & $11.6 \pm 6.1$ & $1.2 \pm 0.5$ & $0.3 \pm 0.4$ & $2.1 \pm 1.1$ \\
\hline $1(18)$ & $2.3 \pm 1.9$ & $10.8 \pm 6.4$ & $1.1 \pm 0.5$ & $0.3 \pm 0.2$ & $2.3 \pm 1.1$ \\
\hline \multicolumn{6}{|l|}{ Lymph vessel invasion } \\
\hline $0(29)$ & $1.8 \pm 1.9$ & $12.1 \pm 7.3$ & $1.2 \pm 0.6$ & $0.3 \pm 0.2$ & $2.2 \pm 1.2$ \\
\hline $1(17)$ & $2.9 \pm 2.4$ & $10.0 \pm 3.7$ & $1.1 \pm 0.5$ & $0.4 \pm 0.5$ & $2.2 \pm 0.9$ \\
\hline $2(1)$ & 1.5 & 9.0 & 1.2 & 0.2 & 1.0 \\
\hline
\end{tabular}

B, Association by immunohistochemical analysis

\begin{tabular}{|c|c|c|c|c|c|}
\hline Feature (n) & TS & DPD & FPGS & GGH & DHFR \\
\hline Total (46) & $27.2 \pm 36.6$ & $94.0 \pm 63.6$ & $225.8 \pm 36.5$ & $120.5 \pm 57.8$ & $90.2 \pm 50.4$ \\
\hline \multicolumn{6}{|l|}{ Gender } \\
\hline Female (25) & $19.5 \pm 32.0$ & $11.3 \pm 6.2$ & $226.6 \pm 35.3$ & $125.8 \pm 62.8$ & $80.4 \pm 47.9$ \\
\hline Male (21) & $36.2 \pm 40.4$ & $79.3 \pm 61.7$ & $224.8 \pm 38.8$ & $114.3 \pm 52.0$ & $101.9 \pm 52.0$ \\
\hline \multicolumn{6}{|l|}{ Age, years } \\
\hline$<70(32)$ & $27.0 \pm 34.0$ & $91.6 \pm 64.5$ & $227.3 \pm 38.0$ & $126.7 \pm 52.0$ & $93.0 \pm 44.4$ \\
\hline$\geq 70(14)$ & $27.5 \pm 43.4$ & $77.5 \pm 58.5$ & $222.1 \pm 34.0$ & $106.4 \pm 69.5$ & $83.9 \pm 63.5$ \\
\hline \multicolumn{6}{|l|}{ Histology subtype } \\
\hline Papillary (23) & $22.3 \pm 36.2$ & $94.1 \pm 67.3$ & $222.2 \pm 36.8$ & $126.5 \pm 65.3$ & $87.4 \pm 55.1$ \\
\hline Acinar (16) & $34.9 \pm 40.6$ & $85.6 \pm 54.5$ & $234.4 \pm 33.7$ & $111.3 \pm 56.2$ & $96.9 \pm 43.8$ \\
\hline Solid (3) & $30.0 \pm 31.2$ & $100.0 \pm 100.0$ & $228.3 \pm 50.6$ & $106.7 \pm 15.3$ & $100.0 \pm 39.1$ \\
\hline Lepidic (2) & $7.0 \pm 7.1$ & $60.0 \pm 28.3$ & $230.0 \pm 56.6$ & $105.0 \pm 35.4$ & $30.0 \pm 14.1$ \\
\hline Lepidic + papillary (1) & 3 & 10 & 210 & 145 & 60 \\
\hline Other (1) & 70 & 50 & 170 & 180 & 170 \\
\hline
\end{tabular}


Table I. Continued.

$\mathrm{B}$, Association by immunohistochemical analysis

\begin{tabular}{|c|c|c|c|c|c|}
\hline Feature (n) & TS & DPD & FPGS & GGH & DHFR \\
\hline \multicolumn{6}{|l|}{ Grade of differentiation } \\
\hline $1(2)$ & $2.5 \pm 0.7$ & $45.0 \pm 49.5$ & $240.0 \pm 42.4$ & $112.5 \pm 46.0$ & $40.0 \pm 28.3$ \\
\hline $2(26)$ & $22.7 \pm 35.6$ & $88.7 \pm 59.0$ & $222.7 \pm 32.7$ & $131.2 \pm 61.9$ & $76.2 \pm 51.5$ \\
\hline $3(18)$ & $36.3 \pm 38.6$ & $90.0 \pm 69.5$ & $228.6 \pm 42.5$ & $106.1 \pm 51.9$ & $116.1 \pm 38.4$ \\
\hline Pleural invasion & a & & & & \\
\hline $0(26)$ & $18.5 \pm 28.4$ & $93.1 \pm 65.9$ & $219.0 \pm 34.8$ & $116.3 \pm 48.7$ & $82.5 \pm 53.5$ \\
\hline $1(14)$ & $46.6 \pm 49.2$ & $76.1 \pm 52.3$ & $238.6 \pm 38.6$ & $120.0 \pm 64.3$ & $101.8 \pm 53.2$ \\
\hline $2(3)$ & $13.0 \pm 10.4$ & $70.0 \pm 62.5$ & $250.0 \pm 30.0$ & $200.0 \pm 80.0$ & $91.7 \pm 27.5$ \\
\hline $3(3)$ & $26.0 \pm 16.4$ & $106.7 \pm 97.1$ & $200.0 \pm 26.5$ & $80.0 \pm 10.0$ & $101.7 \pm 17.6$ \\
\hline \multicolumn{6}{|l|}{ Blood vessel invasion } \\
\hline $0(28)$ & $21.5 \pm 32.6$ & $88.0 \pm 63.6$ & $221.4 \pm 34.4$ & $125.5 \pm 66.0$ & $87.7 \pm 53.0$ \\
\hline $1(18)$ & $35.9 \pm 41.6$ & $86.1 \pm 62.4$ & $232.5 \pm 39.6$ & $112.8 \pm 42.8$ & $94.2 \pm 47.3$ \\
\hline Lymph vessel invasion & a & & & & a \\
\hline $0(29)$ & $17.6 \pm 27.3$ & $88.1 \pm 68.4$ & $221.4 \pm 38.9$ & $122.6 \pm 57.7$ & $76.4 \pm 43.2$ \\
\hline $1(16)$ & $42.1 \pm 46.1$ & $85.0 \pm 54.4$ & $231.6 \pm 32.0$ & $116.9 \pm 61.5$ & $113.4 \pm 56.0$ \\
\hline $2(1)$ & 65 & 100 & 260 & 120 & 120 \\
\hline
\end{tabular}

The difference in total number of the patients between Table IA and B reflects the success rates of IHC and RT-PCR. Each number shows the mean \pm standard deviation. ${ }^{a} \mathrm{P}<0.05$ using the t-test for the top two items in the number of patients. TS, thymidylate synthase; DPD, dihydropyrimidine dehydrogenase; FPGS, folylpolyglutamate synthetase; GGH, $\gamma$-glutamyl hydrolase; DHFR, dihydrofolate reductase.

coefficient, and $|r|$ values $>0.6$ were considered to be statistically significant. Statistical analysis was performed using JMP software for Windows, version 9.0 (SAS Institute Inc., Cary, NC, USA).

\section{Results}

A total of 50 patients with non-Sq NSCLC met the criteria, and their clinical data were collected (Table I). Of the 50 patients, 28 patients were women and 22 patients were men with a median age of 65.5 years (range, $40-78$ years). All patients exhibited an adenocarcinoma-type histology, with the subtypes of a papillary pattern in 25 patients, an acinar pattern in 18 patients, a solid pattern in 3 patients, a lepidic pattern in 2 patients, and a lepidic plus papillary pattern in 1 patient; the subtype could not be determined in 1 patient due to poor differentiation. The differentiation grade $(\mathrm{G})$ in 2, 27, and 18 tumors was classified as well differentiated (G1), moderately differentiated (G2), and poorly differentiated (G3), respectively, according to the histological criteria of the Japan Lung Cancer Society (17). The differentiation data for 3 of the patients were not available. Levels of mRNA expression and IHC scores for folic acid-associated enzymes were assessable in 47 and 46 patients (Table IA and B).

mRNA expression of folic acid-associated enzymes and baseline clinical factors. The mRNA expression levels of each enzyme are shown in Table IA. Significantly higher levels of TS mRNA were observed in G3 compared with $\mathrm{G} 2$ tumors $(\mathrm{P}=0.0399)$, whereas the difference in the IHC score of TS was not significant with respect to clinical factors (Table IB). Analysis of the other four enzymes did not reveal any trend with respect to the baseline clinical factors.

Protein expression of folic acid-associated enzymes and baseline clinical factors. The IHC scores for each enzyme are shown in Table IB. TS was significantly higher in the patients with pleural invasion (P1) compared with in the patients that lacked it ( $\mathrm{P} 0 ; \mathrm{P}=0.027)$. TS and DHFR levels were significantly higher in the patients with lymphatic invasion (Ly1) compared with the patients that lacked it (Ly0; $\mathrm{P}=0.030$ and 0.0173 , respectively). DHFR levels were significantly higher in poorly differentiated cancer $(\mathrm{P}=0.0137)$. The DPD, FPGS, and GGH enzymes did not exhibit any trend with respect to the baseline clinical factors. Scattered, but moderate or strong, staining for FPGS, GGH, and DHFR were observed in bronchial epithelial cells, together with DHFR staining in alveolar epithelial cells and various intensities of immunoreactivity in alveolar macrophages for all five enzymes.

Correlation between $m R N A$ and protein expression. The correlation between mRNA expression and IHC score in the five enzymes is shown in Table II and Fig. 1A-E. There was a significant association between mRNA expression and the IHC score in TS $(r=0.627)$, whereas no distinct correlation was identified between them with the other four enzymes. TS mRNA showed a significant association with GGH mRNA ( $r=0.601)$. 
Table II. Correlations of expression in five enzymes between (A) each mRNA, (B) each IHC score, and (C) each mRNA and the IHC score.

A, Correlation of expression of the five enzymes between each mRNA

\begin{tabular}{|c|c|c|c|c|c|}
\hline & TS mRNA & DPD mRNA & FPGS mRNA & GGH mRNA & DHFR mRNA \\
\hline TS mRNA & 1.000 & 0.036 & -0.171 & 0.601 & 0.408 \\
\hline DPD mRNA & - & 1.000 & 0.540 & -0.174 & 0.320 \\
\hline FPGS mRNA & - & - & 1.000 & -0.144 & 0.353 \\
\hline GGH mRNA & - & - & - & 1.000 & 0.127 \\
\hline DHFR mRNA & - & - & - & - & 1.000 \\
\hline
\end{tabular}

B, Correlation of expression of the five enzymes between each IHC score

\begin{tabular}{|c|c|c|c|c|c|}
\hline & TS mRNA & DPD mRNA & FPGS mRNA & GGH mRNA & DHFR mRNA \\
\hline TS IHC & 1.000 & -0.024 & 0.115 & 0.185 & 0.586 \\
\hline DPD IHC & - & 1.000 & -0.063 & -0.215 & 0.044 \\
\hline FPGS IHC & - & - & 1.000 & 0.005 & 0.023 \\
\hline GGH IHC & - & - & - & 1.000 & 0.081 \\
\hline DHFR IHC & - & - & - & - & 1.000 \\
\hline
\end{tabular}

C, Correlation of expression of the five enzymes between each mRNA and the IHC score

\begin{tabular}{lccccc}
\hline & TS mRNA & DPD mRNA & FPGS mRNA & GGH mRNA & DHFR mRNA \\
\hline TS mRNA & 0.627 & -0.166 & 0.037 & 0.207 & 0.506 \\
DPD mRNA & -0.085 & 0.478 & -0.042 & -0.340 & -0.157 \\
FPGS mRNA & -0.111 & 0.153 & -0.205 & -0.361 & -0.212 \\
GGH mRNA & 0.322 & -0.290 & -0.246 & -0.260 & 0.227 \\
DHFR mRNA & 0.301 & 0.191 & -0.118 & -0.059 & 0.156 \\
\hline
\end{tabular}

IHC, immunohistochemical staining; TS, thymidylate synthase; DPD, dihydropyrimidine dehydrogenase; FPGS, folylpolyglutamate synthetase; GGH, $\gamma$-glutamyl hydrolase; DHFR, dihydrofolate reductase.

Table III. Associations between in vitro tumor sensitivity to drugs assayed using CD-DST and enzyme expression.

\begin{tabular}{|c|c|c|c|c|c|}
\hline & $\mathrm{TS}$ & DPD & FPGS & GGH & DHFR \\
\hline CD-DST & mRNA IHC score & IHC score & IHC score & IHC score & mRNA IHC score \\
\hline
\end{tabular}

Pemetrexed $(\mathrm{n} / \mathrm{n})$

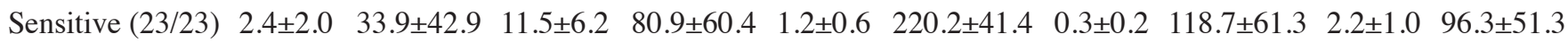

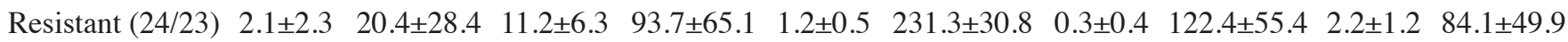

$\mathrm{S}-1(\mathrm{n} / \mathrm{n})$

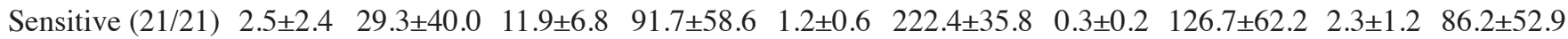

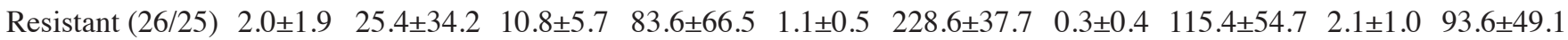

Each number shows the mean \pm standard deviation. CD-DST, collagen gel droplet-embedded culture drug sensitivity test; IHC, immunohistochemical staining; TS, thymidylate synthase; DPD, dihydropyrimidine dehydrogenase; FPGS, folylpolyglutamate synthetase; GGH, $\gamma$-glutamyl hydrolase; DHFR, dihydrofolate reductase; n/n, number of patients used to analyze mRNA/number of patients used to analyze IHC score.

Drug sensitivity and folic acid-associated enzymes. The CD-DST revealed that 23 tumors were sensitive to pemetrexed, and 22 tumors were sensitive to S-1. No significant correlation was identified between the drug sensitivity determined 

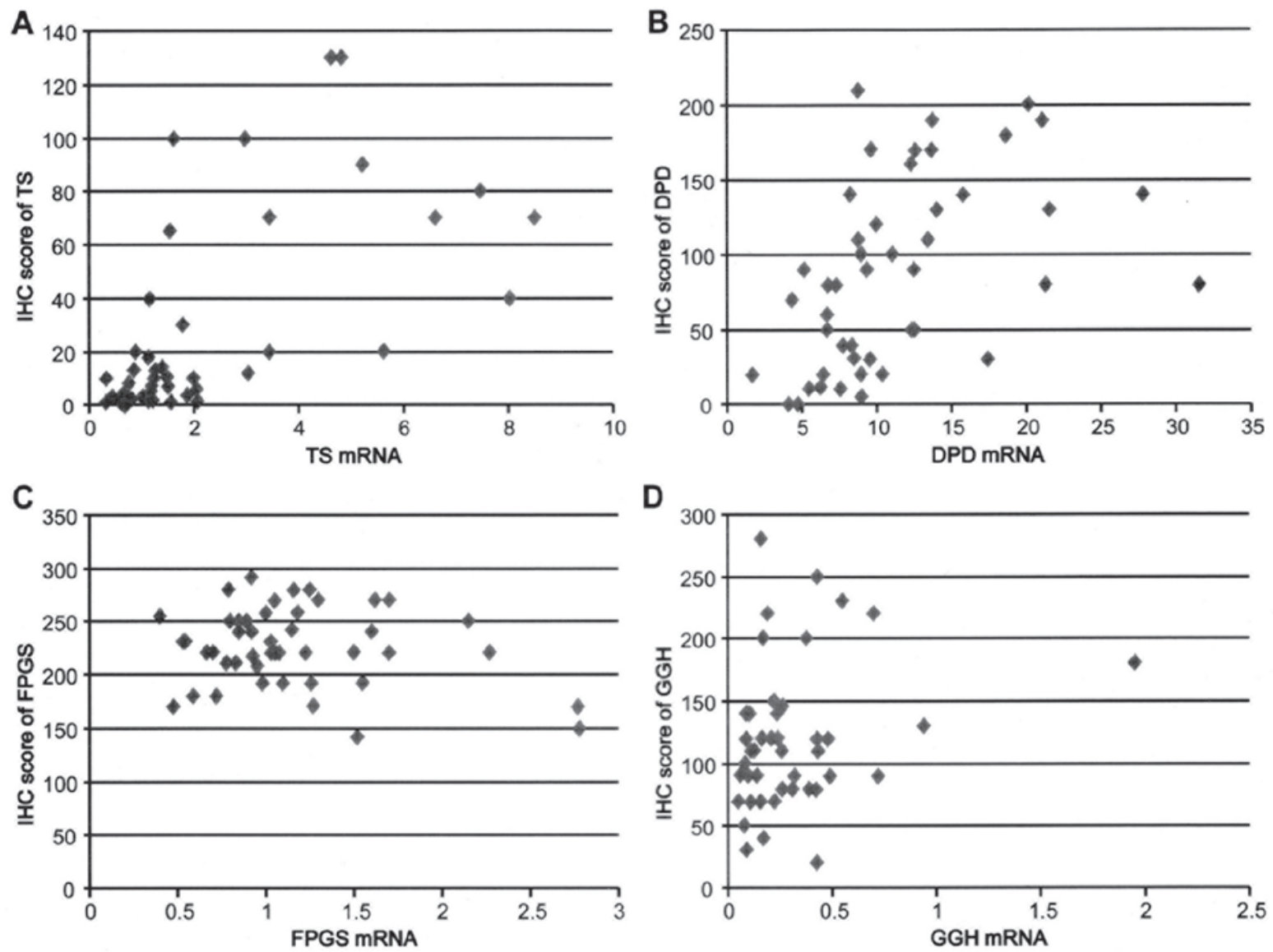

E

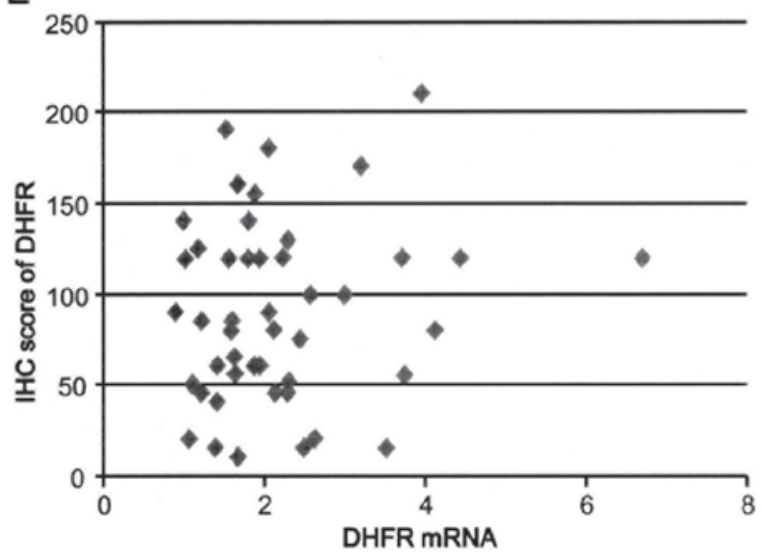

Figure 1. Association between the histological score and gene expression of (A) TS, (B) DPD, (C) FPGS, (D) GGH and (E) DHFR in primary non-small cell lung cancer. TS, thymidylate synthase; DPD, dihydropyrimidine dehydrogenase; FPGS, folylpolyglutamate synthetase; GGH, $\gamma$-glutamyl hydrolase; DHFR, dihydrofolate reductase; IHC, immunohistochemical.

by CD-DST and the expression of each enzyme quantified by mRNA or IHC (Table III). Although TS mRNA expression and the IHC score appeared to be higher in the tumors sensitive to pemetrexed compared with those that were resistant to it, this result was not revealed to be statistically significant. A total of 12 tumors were sensitive to pemetrexed, but not to S-1 (group P), and 11 tumors were sensitive to S-1, but not to pemetrexed (group S). Between these two groups, no significant differences were identified in the expression of each enzyme, quantified either by mRNA or by IHC (Table IV). However, these two groups revealed distinct differences in the grade of tumor differentiation $(\mathrm{P}=0.0008)$ and blood vessel invasion $(\mathrm{P}=0.0069)$ (Table $\mathrm{V}$ ). Group $\mathrm{S}$ contained no G3 tumors, whereas group P contained no G1 tumors (Table VI).

\section{Discussion}

To the best of our knowledge, this is the first study that has compared the mRNA and protein expression of five folic acid-associated enzymes, and determined their sensitivity to pemetrexed and S-1 using resected NSCLC tumors. The correlation between folic acid-associated enzymes and the activity of TS inhibitors in lung cancer has previously been summarized in several reports of meta-analysis $(7,18)$. 
Table IV. Enzyme expression among two groups (designated P and S) featuring different sensitivity to drugs.

\begin{tabular}{|c|c|c|c|c|c|c|c|c|c|c|}
\hline \multirow[b]{2}{*}{ CD-DST } & \multicolumn{2}{|c|}{$\mathrm{TS}$} & \multicolumn{2}{|c|}{ DPD } & \multicolumn{2}{|c|}{ FPGS } & \multicolumn{2}{|c|}{ GGH } & \multicolumn{2}{|c|}{ DHFR } \\
\hline & mRNA & IHC score & mRNA & IHC score & mRNA & IHC score & mRNA & IHC score & mRNA & IHC score \\
\hline Group $P(n=12)$ & $2.0 \pm 1.3$ & $33.9 \pm 42.9$ & $11.1 \pm 6.8$ & $80.8 \pm 68.0$ & $1.1 \pm 0.6$ & $222.9 \pm 44.0$ & $0.3 \pm 0.2$ & $110.0 \pm 46.9$ & $2.1 \pm 1.0$ & $95.4 \pm 51.6$ \\
\hline Group $S^{a}(n=10)$ & $2.1 \pm 2.4$ & $24.3 \pm 34.1$ & $11.9 \pm 8.2$ & $103.5 \pm 63.8$ & $1.2 \pm 0.5$ & $228.0 \pm 31.2$ & $0.3 \pm 0.2$ & $125.0 \pm 47.9$ & $2.4 \pm 1.6$ & $74.0 \pm 52.3$ \\
\hline
\end{tabular}

For Group P, tumors had sensitivity only to pemetrexed and not to S-1, according to the CD-DST results. For Group S, tumors had sensitivity only to S-1 and not to pemetrexed, according to CD-DST. aDifferentiation data are absent for one patient in group S. Each number represents the mean \pm standard deviation. CD-DST, collagen gel droplet-embedded culture drug sensitivity test; IHC, immunohistochemical staining; TS, thymidylate synthase; DPD, dihydropyrimidine dehydrogenase; FPGS, folylpolyglutamate synthetase; GGH, $\gamma$-glutamyl hydrolase; DHFR, dihydrofolate reductase.

Table V. Clinical factors and drug sensitivity.

\begin{tabular}{lccc}
\hline Variables & Group P (n) & Group S (n) ${ }^{\mathrm{a}}$ & P-value \\
\hline $\begin{array}{l}\text { Total } \\
\text { Gender (female/male) }\end{array}$ & $5 / 7$ & 11 & \\
$\begin{array}{l}\text { Age } \\
\quad(<70 / \geq 70 \text { years) }\end{array}$ & $9 / 3$ & $5 / 6$ & 0.140 \\
$\begin{array}{l}\text { Histology subtype } \\
\text { (papillary/acinar/other) }\end{array}$ & $7 / 2 / 3$ & $7 / 3 / 1$ & 0.548 \\
$\begin{array}{l}\text { Grade of differentiation } \\
(1 / 2 / 3)\end{array}$ & $0 / 4 / 8$ & $1 / 9 / 0$ & 0.0008 \\
$\begin{array}{l}\text { Pleural invasion } \\
\quad(0 / 1 / 2 / 3)\end{array}$ & & & \\
$\begin{array}{l}\text { Blood vessels invasion } \\
(0 / 1)\end{array}$ & $5 / 4 / 1 / 2$ & $6 / 5 / 0 / 0$ & 0.229 \\
$\begin{array}{l}\text { Lymph vessels invasion } \\
(0 / 1 / 2)\end{array}$ & $9 / 8$ & $10 / 1$ & 0.0069 \\
\hline
\end{tabular}

For Group P, tumors had sensitivity only to pemetrexed and not to S-1, according to the CD-DST results. For Group S, tumors had sensitivity only to S-1 and not to pemetrexed, according to CD-DST.

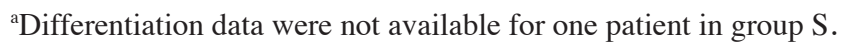

However, TS was assessed either by mRNA expression using RT-PCR or by protein content using IHC, and comparison of the two methods has rarely occurred in the studies in these meta-analyses. Typically, all studies included in a meta-analysis have featured TS measurement by mRNA or IHC (19). It is important to determine the correlation between TS mRNA and TS protein expression in lung cancer in order to gain an improved understanding of the results reported in these studies; an appreciable volume of data on the correlation between these in gastric cancer already exists. The present study has shown that mRNA and protein expression of TS revealed a significant correlation, as identified in the previous reports (20-22), whereas there was a marked discrepancy between mRNA expression levels and IHC scores in FPGS, GGH, and DHFR. A similar discrepancy between the mRNA and IHC of TS in large-cell carcinoma of lung cancer, and DPD in gastric cancer, has already been reported in several studies $(21,23)$. These discrepancies may be due to a limited quantification of IHC, for example, in cases where a random selection of areas in the slides are to be evaluated. However, any contribution resulting from this type of selection bias was unlikely in the present study, since the total area in a tumor section was evaluated by IHC quantification. Various intensities of IHC staining of enzymes in the normal surrounding structure of a tumor, as observed in the present study, may have hampered the results. A weak correlation was observed between TS and DHFR in terms of mRNA expression and the results from IHC. This is consistent with the report by Sowers et al (24), which revealed that mRNA levels of E2F-1, a transcription factor for the two enzymes, were co-associated with the mRNA expression of DHFR and TS in osteosarcoma.

TS is an important target in cancer chemotherapy. Experimentally, low TS levels generally lead to improved effects of TS inhibitors. Certain previous studies revealed no association between TS expression and the response to pemetrexed, whereas other studies revealed that low TS expression was associated with a high sensitivity to pemetrexed-based chemotherapy (25-27); a meta-analysis favored the latter in $\operatorname{NSCLC}(7,18)$. It has also been reported that IHC more accurately predicts the response rate of pemetrexed compared with RT-qPCR, probably because TS protein, but not TS mRNA, exerts activity on DNA synthesis (28). In the present study, the tumors that were sensitive to pemetrexed on performing the CD-DST analysis revealed a slightly higher IHC score for TS compared with those without the sensitivity $(\mathrm{P}=0.217)$.

TS expression is also regulated by cell proliferation and tumor differentiation, and the reaction catalyzed by TS is affected by the activity of the other folic acid-associated enzymes. In the present study, TS mRNA expression increased, along with lowering tumor differentiation, as identified in the previous report (29), and the TS IHC score exhibited a similar tendency. The TS IHC score increased with an increased tendency of pleural invasion and lymphatic invasion, which is consistent with poor differentiation of the tumors. Although the DHFR IHC score increased markedly along with the decreasing grade of tumor differentiation and lymphatic invasion, the expression of the other enzymes did not exhibit a meaningful correlation with tumor differentiation and lymphatic invasion. 
No predictive factors to select pemetrexed or S-1 preferentially by mRNA measurement or IHC were identified in the present study. Instead, the results suggested that these drugs should be selectively used depending on the pathological features of the tumors. Pemetrexed is more useful than S-1 for poorly differentiated adenocarcinoma or those with a high tendency of blood vessel invasion, regardless of histological subtype, whereas S-1 may be more useful than pemetrexed for well-differentiated adenocarcinoma.

In conclusion, the mRNA and protein expression levels of five folic acid-associated enzymes with resected NSCLC tumor specimens were measured to determine biomarkers for targeting TS inhibitors. The results demonstrated a poor correlation between mRNA and IHC in the expression of these enzymes, with the exception of TS. The expression levels of TS, determined either by mRNA analysis or by IHC, failed to reveal any clear association with sensitivity to pemetrexed or $\mathrm{S}-1$ when cytotoxicity was analyzed in an ex vivo model. The only factors that demonstrated any potential to discriminate between the cytotoxicity of pemetrexed and S-1 were the grade of tumor differentiation and vascular invasion: Tumors showing G3 differentiation or advanced vascular invasion appeared to be more sensitive to pemetrexed, whereas those with G1 or G2 differentiation were more sensitive to $\mathrm{S}-1$.

\section{Acknowledgements}

The present study was funded by Taiho Pharmaceutical Co., Ltd. (Tokyo, Japan). The present study was also partly supported by grants from the Osaka Foundation for the Prevention of Cancer and Cardiovascular Diseases. We thank the patients and their families for their co-operation.

\section{References}

1. Hanna N, Shepherd FA, Fossella FV, Pereira JR, De Marinis F, von Pawel J, Gatzemeier U, Tsao TC, Pless M, Muller T, et al: Randomized phase III trial of pemetrexed versus docetaxel in patients with non-small-cell lung cancer previously treated with chemotherapy. J Clin Oncol 22: 1589-1597, 2004.

2. Scagliotti GV, Parikh P, von Pawel J, Biesma B, Vansteenkiste J, Manegold C, Serwatowski P, Gatzemeier U, Digumarti R, Zukin M, et al: Phase III study comparing cisplatin plus gemcitabine with cisplatin plus pemetrexed in chemotherapy-naive patients with advanced-stage non-small-cell lung cancer. J Clin Oncol 26: 3543-3551, 2008.

3. Ciuleanu T, Brodowicz T, Zielinski C, Kim JH, Krzakowski M, Laack E, Wu YL, Bover I, Begbie S, Tzekova V, et al: Maintenance pemetrexed plus best supportive care versus placebo plus best supportive care for non-small-cell lung cancer: A randomised, double-blind, phase 3 study. Lancet 374: 1432-1440, 2009.

4. Okamoto I, Yoshioka H, Morita S, Ando M, Takeda K, Seto T, Yamamoto N, Saka H, Asami K, Hirashima T, et al: Phase III trial comparing oral S-1 plus carboplatin with paclitaxel plus carboplatin in chemotherapy-naïve patients with advanced non-small-cell lung cancer: Results of a west Japan oncology group study. J Clin Oncol 28: 5240-5246, 2010.

5. Kawahara M, Furuse K, Segawa Y, Yoshimori K, Matsui K, Kudoh S, Hasegawa K and Niitani H: Phase II study of S-1, a novel oral fluorouracil, in advanced non-small-cell lung cancer. Br J Cancer 85: 939-943, 2001.

6. Urata Y, Okamoto I, Takeda M, Hattori Y, Okuno K, Shimada T, Kurata T, Kaneda H, Miyazaki M, Terashima M, et al: Phase 2 study of S-1 and carboplatin plus bevacizumab followed by maintenance S-1 and bevacizumab for chemotherapy-naive patients with advanced nonsquamous non-small cell lung cancer. Cancer 119: 2275-2281, 2013.
7. Wang L, Wang R, Pan Y, Sun Y, Zhang J and Chen H: The pemetrexed-containing treatments in the non-small cell lung cancer is -/low thymidylate synthase expression better than +/ high thymidylate synthase expression: A meta-analysis. BMC Cancer 14: 205, 2014.

8. Salonga D, Danenberg KD, Johnson M, Metzger R, Groshen S, Tsao-Wei DD, Lenz HJ, Leichman CG, Leichman L, Diasio RB, et al: Colorectal tumors responding to 5 -fluorouracil have low gene expression levels of dihydropyrimidine dehydrogenase, thymidylate synthase, and thymidine phosphorylase. Clin Cancer Res 6: 1322-1327, 2000.

9. Metzger R, Danenberg K, Leichman CG, Salonga D, Schwartz EL, Wadler S, Lenz HJ, Groshen S, Leichman L and Danenberg PV: High basal level gene expression of thymidine phosphorylase (platelet-derived endothelial cell growth factor) in colorectal tumors is associated with nonresponse to 5-fluorouracil. Clin Cancer Res 4: 2371-2376, 1998.

10. Saito S, Tsuno N, Nagawa H, Sunami E, Zhengxi J, Osada T, Kitayama J, Shibata Y, Tsuruo T and Muto T: Expression of platelet-derived endothelial cell growth factor correlates with good prognosis in patients with colorectal carcinoma. Cancer 88: 42-49, 2000.

11. Bonanomi A, Kojic D, Giger B, Rickenbach Z, Jean-Richard-Dit-Bressel L, Berger C, Niggli FK and Nadal D: Quantitative cytokine gene expression in human tonsils at excision and during histoculture assessed by standardized and calibrated real-time PCR and novel data processing. J Immunol Methods 283: 27-43, 2003.

12. Pérez S, Royo LJ, Astudillo A, Escudero D, Alvarez F, Rodríguez A, Gómez E and Otero J: Identifying the most suitable endogenous control for determining gene expression in hearts from organ donors. BMC Mol Biol 8: 114, 2007.

13. Livak KJ and Schmittgen TD: Analysis of relative gene expression data using real-time quantitative PCR and the 2(-Delta Delta C(T))method. Methods 25: 402-408, 2001.

14. Kobayashi H, Tanisaka K, Doi O, Kodama K, Higashiyama M, Nakagawa H, Miyake M, Taki T, Hara S, Yasutomi M, et al: An in vitro chemosensitivity test for solid human tumors using collagen gel droplet embedded cultures. Int J Oncol 11: 449-455, 1997.

15. Kobayashi H, Higashiyama M, Minamigawa K, Tanisaka K, Takano T, Yokouchi H, Kodama K and Hata T: Examination of in vitro chemosensitivity test using collagen gel droplet culture method with colorimetric endpoint quantification. Jpn J Cancer Res 92: 203-210, 2001.

16. Higashiyama M, Kodama K, Yokouchi H, Takami K, Nakagawa H, Imamura F, Minamigawa K and Kobayashi H: Cisplatin-based chemotherapy for postoperative recurrence in non-small cell lung cancer patients: Relation of the in vitro chemosensitive test to clinical response. Oncol Rep 8: 279-283, 2001.

17. The Japan Lung Cancer Society: General rule for clinical and pathological record of lung cancer. 7th edition. Kanehara \& Co., Ltd., Tokyo, 2010.

18. Liu Q, Yu Z, Xiang Y, Wu N, Wu L, Xu B, Wang L, Yang P, Li Y and Bai L: Prognostic and predictive significance of thymidylate synthase protein expression in non-small cell lung cancer: A systematic review and meta-analysis. Cancer Biomark 15: 65-78, 2015.

19. Wang T, Chuan Pan C, Rui Yu J, Long Y, Hong Cai X, De Yin X, Qiong Hao $\mathrm{L}$ and Li Luo L: Association between TYMS expression and efficacy of pemetrexed-based chemotherapy in advanced non-small cell lung cancer: A meta-analysis. PLoS One 8: e74284, 2013.

20. Ibe T, Shimizu K, Nakano T, Kakegawa S, Kamiyoshihara M, Nakajima T, Kaira K and Takeyoshi I: High-grade neuroendocrine carcinoma of the lung shows increased thymidylate synthase expression compared to other histotypes. J Surg Oncol 102: 11-17, 2010.

21. Sasako M, Terashima M, Ichikawa W, Ochiai A, Kitada K, Kurahashi I, Sakuramoto S, Katai H, Sano T and Imamura H: Impact of the expression of thymidylate synthase and dihydropyrimidine dehydrogenase genes on survival in stage II/III gastric cancer. Gastric Cancer 18: 538-548, 2015.

22. Hou J, Lambers M, den Hamer B, den Bakker MA, Hoogsteden HC, Grosveld F, Hegmans J, Aerts J and Philipsen S: Expression profiling-based subtyping identifies novel non-small cell lung cancer subgroups and implicates putative resistance to pemetrexed therapy. J Thorac Oncol 7: 105-114, 2012. 
23. Monica V, Scagliotti GV, Ceppi P, Righi L, Cambieri A, Lo Iacono M, Saviozzi S, Volante M, Novello S and Papotti M: Differential thymidylate synthase expression in different variants of large-cell carcinoma of the lung. Clin Cancer Res 15: $7547-7552,2009$

24. Sowers R, Toguchida J, Qin J, Meyers PA, Healey JH, Huvos A, Banerjee D, Bertino JR and Gorlick R: mRNA expression levels of E2F transcription factors correlate with dihydrofolate reductase, reduced folate carrier, and thymidylate synthase mRNA expression in osteosarcoma. Mol Cancer Ther 2: 535-541, 2003.

25. Igawa S, Ryuge S, Wada M, Otani S, Maki S, Takakura A, Katono K, Sasaki J, Sato Y and Masuda N: Pemetrexed for previously treated patients with non-small cell lung cancer and differences in efficacy according to thymidylate synthase expression. Chemotherapy 58: 313-320, 2012.

26. Takezawa K, Okamoto I, Okamoto W, Takeda M, Sakai K, Tsukioka S, Kuwata K, Yamaguchi H, Nishio K and Nakagawa K: Thymidylate synthase as a determinant of pemetrexed sensitivity in non-small cell lung cancer. Br J Cancer 104: 1594-1601, 2011.
27. Nicolson MC, Fennell DA, Ferry D, O'Byrne K, Shah R, Potter V, Skailes G, Upadhyay S, Taylor P, André V, et al: Thymidylate synthase expression and outcome of patients receiving pemetrexed for advanced nonsquamous non-small-cell lung cancer in a prospective blinded assessment phase II clinical trial. J Thorac Oncol 8: 930-939, 2013.

28. Ren DN, Kim IY, Koh SB, Chang SJ, Eom M, Yi SY, Seong SH, Kim MD, Bronner MP and Cho MY: Comparative analysis of thymidylate synthase at the protein, mRNA, and DNA levels as prognostic markers in colorectal adenocarcinoma. J Surg Oncol 100: 546-552, 2009.

29. Tanaka F, Wada H, Fukui Y and Fukushima M: Thymidylate synthase (TS) gene expression in primary lung cancer patients: A large-scale study in Japanese population. Ann Oncol 22: 1791-1797, 2011. 